\title{
Intercontinental freight transport impacts: modeling and measuring choice effects
}

\author{
E. Fornasiero \& A. Libardo \\ Transport, Territory and Logistics Research Unit - TTL, \\ University IUAV of Venice, Italy
}

\begin{abstract}
This paper brings to the topic of world shipments an investigation of more efficient multimodal routes from the commercial (time and consumption costs) and environmental (impacts) points of view. In particular, the freight relations existing between Asia and Europe, through the Suez Canal, have been investigated because of the constant growth of these relations, despite the Europe-America ones. European destinations are reached by alternative paths, which use road or railway connections starting from the main Mediterranean (Genova, Venezia, Trieste) or North European (Antwerp, Rotterdam, Hamburg, Bremerhaven) ports. Environmental and commercial index values, evaluated for each possible route through an original software (written in the APL code), allow a comparison in order to identify which is the most sustainable transport chain relating to the different destinations. These results could be useful to re-organize a freight network in terms of managing and adjusting the existing infrastructures in order to obtain lower environmental impacts.
\end{abstract}

Keywords: emissions, multimodal choice, maritime transport, railway transport, road transport.

\section{Study overview and objectives}

A more sustainable transportation chain is sought in accordance with the European goals of planning in order to limit global warming [3], climate change and airborne pollution, thereby reducing emissions of greenhouse gases (such as carbon dioxide, $\mathrm{CO}_{2}$ ). This research aims to optimize the existing use of multimodal networks (ship-train/ship-lorry), particularly for trans-oceanic shipments. Intercontinental freight delivery necessarily implies more 
transportation modes to reach final destinations. Each of these has different performances, efficiencies and environmental impacts. Nowadays freight path choice does not take into account the energy related (production and consumption) environmental externalities and associated costs: ports of call or freight depots, for instance, are selected by the costs incidence or by private agreement between operators. In the study we formalized a model to evaluate the most efficient multimodal corridors considered from the environmental $\left(\mathrm{CO}_{2}\right.$ emissions) and the commercial (transit time and consumptions) points of view. In particularly, the research investigated the freight relations (TEU shipments) existing between Asia and Europe, through the Suez Canal. This is because intercontinental shipping in 2009 showed that European-Asian market (16 million TEUs) relationships have been three times greater than the European to transatlantic (5.2 million TEU) ones. The European destinations were reached by alternative routes, which use road or railway connections starting from the main Mediterranean (Genova, Venezia, Trieste) or North European (Antwerp, Rotterdam, Hamburg, Bremerhaven) ports. Environmental and commercial index values, calculated for each route, allow a comparison to set which is the most sustainable transport chain relating with the different destinations. These results could be useful to re-organize a freight network in terms of managing and adjusting the existing infrastructures to obtain lower environmental impacts.

In detail the study defined:

-the railway network of central Europe, which is capable of achieving combined transport (specifically for containers), in combination with the sea ports of Northern Europe (Rotterdam-Hamburg-Bremerhaven) and Northern Italy (Tyrrhenian and Adriatic Sea);

-the road network in order to compare the value indicators obtained in a maritime-road logistic chain or in a maritime-rail logistic chain;

-the economic area of influence of each port analyzed through transport variables (time) and then environmental parameters (energy consumption and emissions);

-the environmental problems connected with the current economic organization of sea lines and the influence areas of the port systems minimizing environmental impacts;

-alternative scenarios for the most sustainable traffic organization.

The cargo transport performances and the environmental impacts are quite different, depending on the different countries' topology, type of vehicles used, energy carriers used and conversion types, all of which are significant influencing factors: for all of these factors in this research we adopted an average value. The same differences are not relevant considering the energy consumption of similar vehicles in different countries, as in all countries relatively modern trucks of different international manufacturers are usually used for long-distance transport on the road. For ship and air transport, the existing vehicles are likewise used internationally. More differences could exist in railway transport, where the various railway companies employ different locomotives and train configurations. 


\section{Multimodal freight transport network}

\subsection{Container shipping relation Asia-Middle East to Europe}

This research has investigated the International transport chains from AsiaMiddle East to Europe via the Suez Canal and via the European ports until their final destination by rail or road. Multimodal freight transport relates to shipments for which two or more transport modes are used - e.g. ship and train, ship and truck, or ship train and truck. As Port Said could be the gate of Suez Canal, it has been considered as the origin point for the simulation of the different multimodal chains, so the following assumptions have been made:

-maritime routes to North Adriatic and North Tyrrhenian ports are realized through 7,500 TEU capacity ships;

-maritime routes to Atlantic ports are realized with 9,000 TEU capacity ships;

-destinations within a 200-km (124-mile) range from ports are reached by road;

-destinations beyond a 200-km (124-mile) range from ports are served both by rail and road system combinations.

\subsection{The network simulated in the study}

The first part of the study has been devoted to the elaboration of the reference multimodal graph, required by the flow network simulation and traffic-related computation. The multimodal graph is made up as follows:

-the maritime routes from the Suez Canal (gate for the Mediterranean Sea from the Far East), and the three port systems: North Europe (Antwerp, Rotterdam, Bremerhaven, Hamburg), North Tyrrhenian Sea (Genova, la Spezia) and North Adriatic (Venezia, Trieste);

-the landlines (rail-road) between the three port systems and the main destination in Central Europe.

\subsubsection{European sea ports}

The main North European ports, also in terms of traffic volume handled, are: Rotterdam, Antwerp, Bremerhaven and Hamburg. These four ports handle almost 7\% of world traffic totaling a volume of over 30 million TEUs in 2007, of which $30 \%$ is the share of transhipment.

Regarding the North Tyrrhenian Sea, the ports considered while processing the multimodal graph are Genova, La Spezia and Livorno. These ports are, in terms of distances and times, close to each other, and for the subsequent simulations it was decided to consider only the port of Genoa. The main Italian ports bordering the northern Adriatic Sea are two: Venice and Trieste. The volume of traffic in the three Italian ports considered is very relevant for the national market, but they are weak compared to the world volumes. Figure 1 shows the European ports considered in this study and the maritime freight network. 


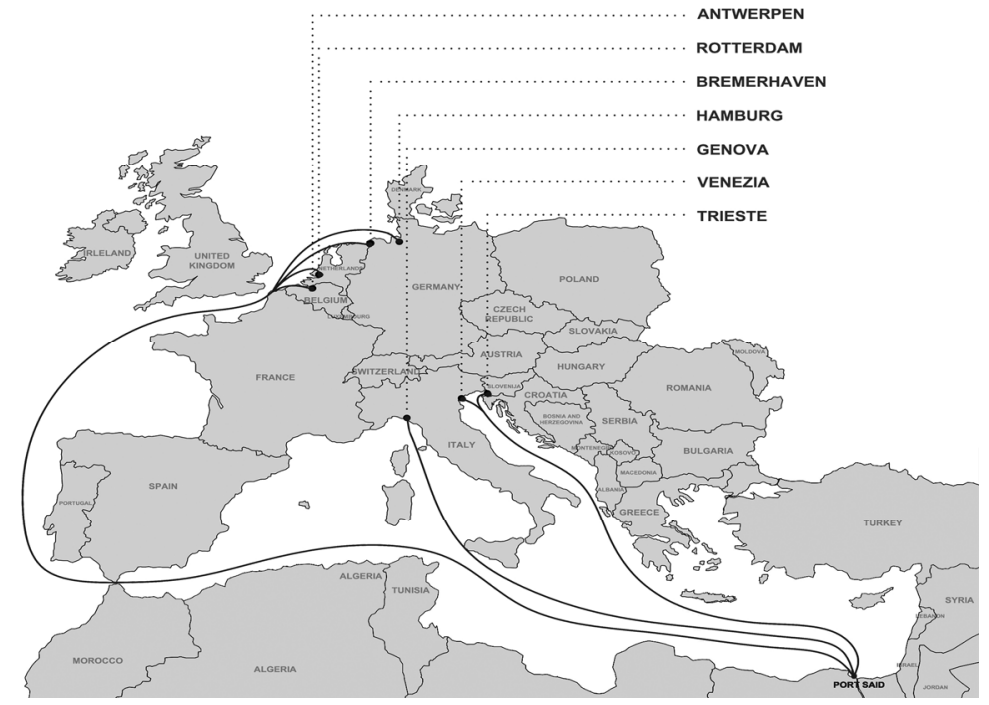

Figure 1: $\quad$ European sea ports and the maritime freight network.

Table 1: $\quad$ Distances Port Said - main European ports.

\begin{tabular}{|c|c|c|c|}
\hline Origin & Destination & Nautical miles & Km \\
\hline Port Said & Rotterdam & 3,274 & 6,063 \\
\hline Port Said & Antwerp & 3,279 & 6,073 \\
\hline Port Said & Bremerhaven & 3,479 & 6,443 \\
\hline Port Said & Hamburg & 3,527 & 6,532 \\
\hline Port Said & Trieste & 1,294 & 2,396 \\
\hline Port Said & Genova & 1,419 & 2,625 \\
\hline Port Said & Venezia & 1,311 & 2,428 \\
\hline Source: Maritime Authority of Venice, 2009 \\
\hline
\end{tabular}

Maritime route distances are derived using data supplied by the maritime Authority of Venice by considering Port Said as the origin (Table 1). Distances of North European ports from Port Said (and Suez Canal) range between 6,000 $\mathrm{km}$ (Rotterdam) and 6,500 km (Hamburg) with travel times, for direct services in ordinary sailing conditions, which range between 7 days (Rotterdam) and 8 days (Hamburg).

The distance from Port Said to the Italian ports considered is 1300-1400 nautical miles and the cruise time for direct services is slightly less than 3 days. However, Maersk services operating between these ports enable the connection Port Said - Trieste in about 3.5 days (with an intermediate stop at Damietta).

\subsubsection{Railway and road freight network}

The railway network and its characteristics have been taken from different sources: The Uniform distance table of international Freight traffic, The International Union of Railways (UIC), 2007 and The Interunit Commission 


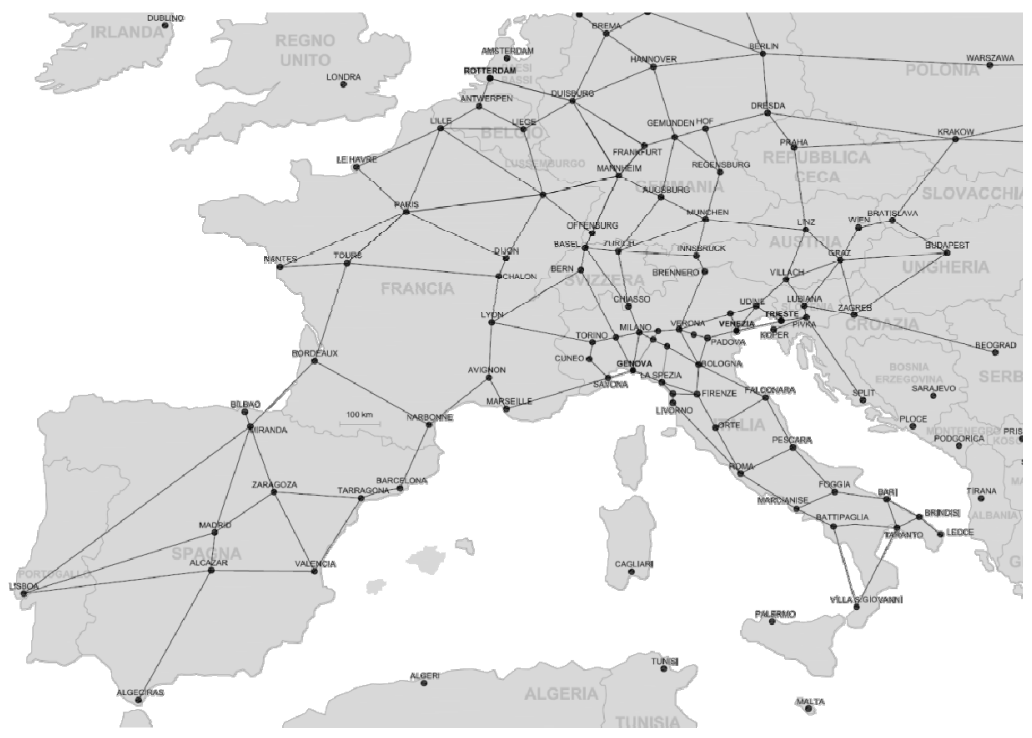

Figure 2: $\quad$ Railway and the European road network.

technique, The International Union of combined Road-Rail transport companies [5]. The nodes correspond to the main freight stations and destination cities. The arches correspond to rail or road (highway) connections as shown in Figure 2.

The routes have been calculated between the place of origin and the destination for each selected traffic type (e.g. road, rail, ship etc.), by means of the shortest or the fastest way. If there is a highway between the origin and the destination the lorries are assumed to use it.

\section{Consumption and emissions}

\subsection{Standard transport modes and propulsion systems}

The transportation of cargo in Europe is carried out by different transport modes. Within this research the most important modes using common vehicle types and propulsion systems are considered:

-road: truck trailers/articulated of about 40 tons gross weight (load capacity 2 TEU, equal to 26 tons), moved by diesel fuel;

-rail: typical train for international transport of about 1000 tons gross weight (load capacity 30 TEU, equal to 400 tons), motored by electricity and diesel;

-ship: container ship medium-high 7500/9000 TEU, moved by fuel oil/marine diesel oil.

Every transport vessel has a maximum loading capacity which is defined by the maximum load weight allowed and the maximum volume available. Since we are dealing with a multimodal chain the cargo units are assumed to be TEU. 
As a consequence of this all the units of measure are transformed in relation with unitary TEU value: consumption and emissions are calculated in $\mathrm{g} / \mathrm{TEU} \mathrm{km}$ for each type of transport.

\subsection{Fuel consumption by mode of transportation}

Road. The energy consumption and emissions of road transport depends on various factors:

- vehicle size and weight, vehicle configuration (trailer), motor concept, transmission

- weight of load (load factor)

- driving pattern: influence of the driver and of the road characteristics (road category, number and width of lines, curves, gradient).

Calculations on the consumption and the emission of the lorries have been performed considering a full loaded vehicle. In particular the average consumption value for a 40 tons truck is equal to $500 \mathrm{~g} / \mathrm{km}$ (source: Volvo Truck Corporation), this correspond at $220 \mathrm{~g} / \mathrm{km} \mathrm{TEU.}$

Rail. The energy consumption and emissions of rail transport depend on various factors (traction type, route characteristics) and particularly on the gross weight of the train.

The standard train which this research refers to, motored by electric traction, according to an IFEU study [4] have an energy consumption of $22 \mathrm{Wh} /$ gross tkm (that corresponds to nearly $62 \mathrm{~g} / \mathrm{TEU} \mathrm{km}$ ); the consumption of a diesel train is close to $5 \mathrm{~g} /$ gross $\mathrm{t} \mathrm{km}$ (that corresponds to nearly $165 \mathrm{~g} / \mathrm{TEU} \mathrm{km}$ ).

Ship. Unitary consumption value have been calculated on the basis of an A.R.P.A.V. Italian study [1] that has determined a methodology to define the consumption in relation to different ship function (container, general cargo and so on). The formalized formula to determinate TEU ship consumption ( $t$ /day) is the following:

$$
\mathrm{C}=8.0052+0.00235^{*} \mathrm{GT}
$$

where GT represents Gross Tonnage

Because of the GT variation, a ship census has been done to correlate capacity (TEU/ship) to GT [2]. To investigate the relationships between the two variables a regression has been applied and a correlation coefficient $r$ show a high value (close to 1). Correlation between ship TEU capacity and Gross Tonnage GT is reported in Figure 3.

As a consequence of this, it has been evaluated the ship consumption per day in relation with capacity. Daily consumptions are settled on the basis of the distance covered of $756 \mathrm{~km}$ at an average service speed of 17 knots and then it has been referred to different ship capacities, as shown in Table 2. 


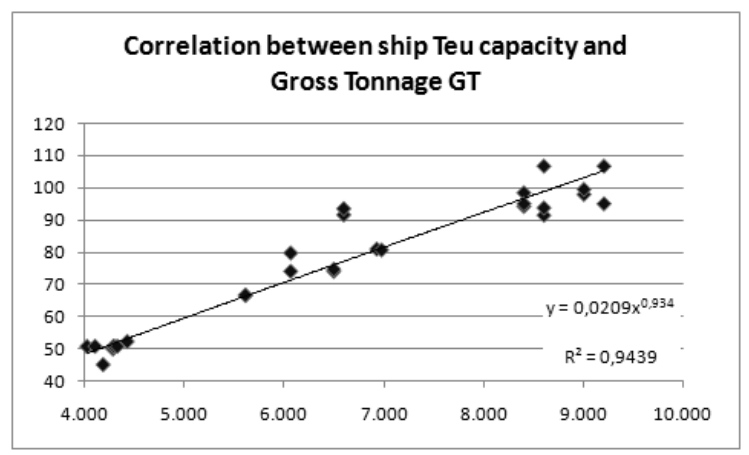

Figure 3: $\quad$ Correlation between ship TEU capacity and Gross Tonnage (GT).

Table 2: Dimensions of ship elements and fuel consumption.

\begin{tabular}{|c|c|c|c|}
\hline TEU/ship & GT & $\begin{array}{c}\text { Consumption } \\
{[\mathbf{t} / \mathbf{d a y}]}\end{array}$ & $\begin{array}{c}\text { Consumption } \\
{[\mathbf{g} / \mathbf{k m} \text { TEU] }}\end{array}$ \\
\hline 5,000 & 59.564 & 148,03 & 39.18 \\
\hline 5,500 & 65.110 & 161,06 & 38.76 \\
\hline 6,000 & 70.622 & 174,02 & 38.38 \\
\hline 6,500 & 76.104 & 186,90 & 38.05 \\
\hline 7,000 & 81.558 & 199,72 & 37.76 \\
\hline 7,500 & 86.987 & 212,47 & 37.49 \\
\hline 8,000 & 92.392 & 225,18 & 37.25 \\
\hline 8,500 & 97.774 & 237,82 & 37.03 \\
\hline 9,000 & 103.136 & 250,42 & 36.82 \\
\hline \multicolumn{4}{|r}{ Source: Our elaboration on Containerization International data } \\
\hline
\end{tabular}

\subsection{Emissions by mode of transportation}

Emissions produced by the transport system are the following: Carbon dioxide $\left(\mathrm{CO}_{2}\right)$, Nitrogen oxides (NOx), Sulfur oxides (SOx), Non-methane volatile organic compounds (NMVOC) Particulate Matter (PM).

As the relevant literature of the field clearly states, emissions are the direct consequence of two processes:

a) the conversion of primary energy into secondary energy;

b) the consumption of the delivered energy for producing motion, through the transformation of secondary energy into mechanic or electric power.

The first process has a uniform distribution over time, particularly in terms of fossil fuels. This is due to the fact that plants necessary for transforming primary energy require long-terms plans and relevant investments. The second process produces variable emissions over time (increased efficiency of motors) and space (uneven distribution of efficient or electric vehicles through different areas). On the other hand, secondary energy consumption depends also from the choice of the propelling system.

For instance, if one considers the - electric-powered - rail transport, no emissions are to be ascribed to the actual transportation process. In the case of maritime or road transport emissions depend from the mechanic technologies 
adopted. Typically, technological innovation allows one to decrease the levels of emission due to the use of secondary energy, but not the quantity of energy involved in the processes.

Hence, in order to achieve objective and stable results, comparable over time, we decided to focus only on the primary energy consumption associated to the transport of goods. The results described in the following show that, typically, decisions on the transport modes to be used are not made taking into account the environmental concerns. The figures obtained would be even worse if also emissions due to secondary energy consumption were considered. The data used for simulating transports are realistic, and they have been validated by experts. By using the same data it would be possible to perform an analysis of the final consumption.

The results presented here can be considered as objective strategic parameters: As mentioned above, they would not be significantly affected by a technological improvement of the propulsion system of transport means.

Further, if emissions due to final energy transformation were taken into account, the ground system, relying on electric-powered rail systems would provide competitive benefits in terms of sustainability with respect to other transport modes, for a time that cannot be quantified a priori. For this reason the methodology used in the present study is the most suitable to provide sound and reliable results in relation to the current characteristics of the transportation market.

The relation between fuel and emission is reported in table 3 .

The environmental impacts considered are linked to the generation of final energy and they do not include the production and maintenance of vehicles, the construction and maintenance of transport infrastructure, any additional consumption of resources, such as administration buildings, stations and airports.

The elaboration of the data described above allows the production of the results shown in table 4 .

\section{Simulation parameters and results}

\subsection{Simulation methodology and procedure}

The multimodal networks have been defined as arcs (rail and road links) and nodes (ports, goods yards, logistic centers). Efficiency and environmental

Table 3: $\quad$ Emission factors (grams) related to final energy (kg fuel).

\begin{tabular}{|c|c|c|c|c|c|}
\hline Fuel & $\mathbf{C O}_{2}$ & Nox & SO2 & NMVOC & PM \\
\hline $\mathrm{kg}$ & grams & grams & grams & grams & grams \\
\hline Gasoline & 670 & 2.2 & 6.2 & 2.1 & 0.3 \\
\hline Diesel & 470 & 1.8 & 4.4 & 1.5 & 0.24 \\
\hline Kerosene & 450 & 1.8 & 4.3 & 1.5 & 0.23 \\
\hline $\begin{array}{c}\text { Marine } \\
\text { diesel oil }\end{array}$ & 400 & 1.7 & 4 & 1.5 & 0.22 \\
\hline \multicolumn{2}{|r|}{} \\
\hline
\end{tabular}


Table 4: $\quad$ Emission factors (grams) related to final energy (kg fuel).

\begin{tabular}{|c|c|c|c|c|c|c|c|}
\hline \multicolumn{8}{|c|}{ VALUE OF EMISSIONS PER TEU - KM } \\
\hline & $\begin{array}{l}\text { Power } \\
\text { Source }\end{array}$ & $\begin{array}{c}\mathrm{CO}_{2} / \mathrm{TEU} \\
-\mathrm{km} \\
\text { (grams) }\end{array}$ & $\begin{array}{c}\mathrm{NOx} / \mathrm{TEU} \\
-\mathrm{km} \\
\text { (grams) }\end{array}$ & $\begin{array}{c}\mathrm{SO} 2 / \mathrm{TEU} \\
-\mathrm{km} \\
\text { (grams) }\end{array}$ & $\begin{array}{l}\text { NMVOC/TEU- } \\
\text { km (grams) }\end{array}$ & $\begin{array}{l}\mathrm{PM} / \mathrm{TEU} \\
-\mathrm{km} \\
\text { (grams) }\end{array}$ & $\begin{array}{c}\text { total } \\
\text { grams/TEU } \\
-\mathrm{km}\end{array}$ \\
\hline TRAIN & Electric & 29.314 & 0.112 & 0.274 & 0.094 & 0.015 & 29.81 \\
\hline & $\begin{array}{c}\text { Diesel } \\
\text { /Electric }\end{array}$ & 77.550 & 0.297 & 0.726 & 0.248 & 0.040 & 78.86 \\
\hline TRUCK & Diesel & 103.400 & 0.396 & 0.968 & 0.330 & 0.053 & 105.15 \\
\hline SHIP 7.500 TEU & Average & 16.128 & 0.065 & 0.154 & 0.054 & 0.008 & 16.41 \\
\hline SHIP 9.000 TEU & $\begin{array}{l}\text { on the } \\
\text { basis of } \\
\text { different } \\
\text { engine }\end{array}$ & 16.005 & 0.064 & 0.153 & 0.053 & 0.008 & 16.28 \\
\hline
\end{tabular}

impacts of transport chains are estimated using APL Language Program in relation to the following parameters:

- average transit times (minutes) calculated on the basis of distances between network nodes:

- transit times of ship container transport services, are deducted on an average cruise speed of $17 \mathrm{knots}$. This value was calculated in relation to the real transit time recorded on the corresponding trade line (source: shipping companies, Maersk, MSC, and others);

- running times of rail services, have been simulated in relation at a commercial speed of $40 \mathrm{~km} / \mathrm{h}(25 \mathrm{mph})$. This value has been validated by the RailNetEurope (RNE), an association formed by a majority of European Rail Infrastructure Managers;

- travel times of truck services have been performed on road network by applying an All-or-Nothing assignment model with flow control. This model assumed that travel time could vary with congestion. The model has been calibrated on the data reported by the European freight road companies and in relation with freight slots designed by infrastructure managers.

- consumptions have been calculated in KOE Kilogram of Oil Equivalent correlating unitary values (see par. 3.2) and run distances, for each intermodal route.

- emissions have been calculated in $\mathrm{kg} / \mathrm{TEU}$ using unitary values (see par. 3.3) and run distances, for each intermodal route.

\subsection{Results}

First of all the elaborations performed in this research have allowed:

-picking up the multimodal freight transport combinations related to shipments, for example ship+train, ship+truck, ship+train+truck; 
-accounting transit time, total energy consumption and emissions on every alternative path that could serve the main European destinations, using multimodal network and different integrated transport modes.

Finally the most efficient multimodal route has been evaluated for each indicator (origin in Port Said): figure 4 shows the results for one examined destination (Paris).

The lower value for consumption and emissions is reached by the route (sea+rail) via Genova, even if the lower transit time is achievable via Venezia (sea plus road). The emissions resulting from ship+road routes are visibly greater than ship+rail alternatives, which have obviously less impact on the environment.

The same analysis has been performed in relation with six other origin/destination cases too: Port Said-Metz, Port Said-Munich, Port Said-Praha, Port Said-Krakov, Port Said-Wien, Port Said-Kyjiv. The final destinations have been chosen cause of referring each one to the main European trading areas. For every destination we can identify the four best routes, in terms of: distances, transit time, energy consumption and emissions. Figure 5 synthesizes the results of the elaborations.

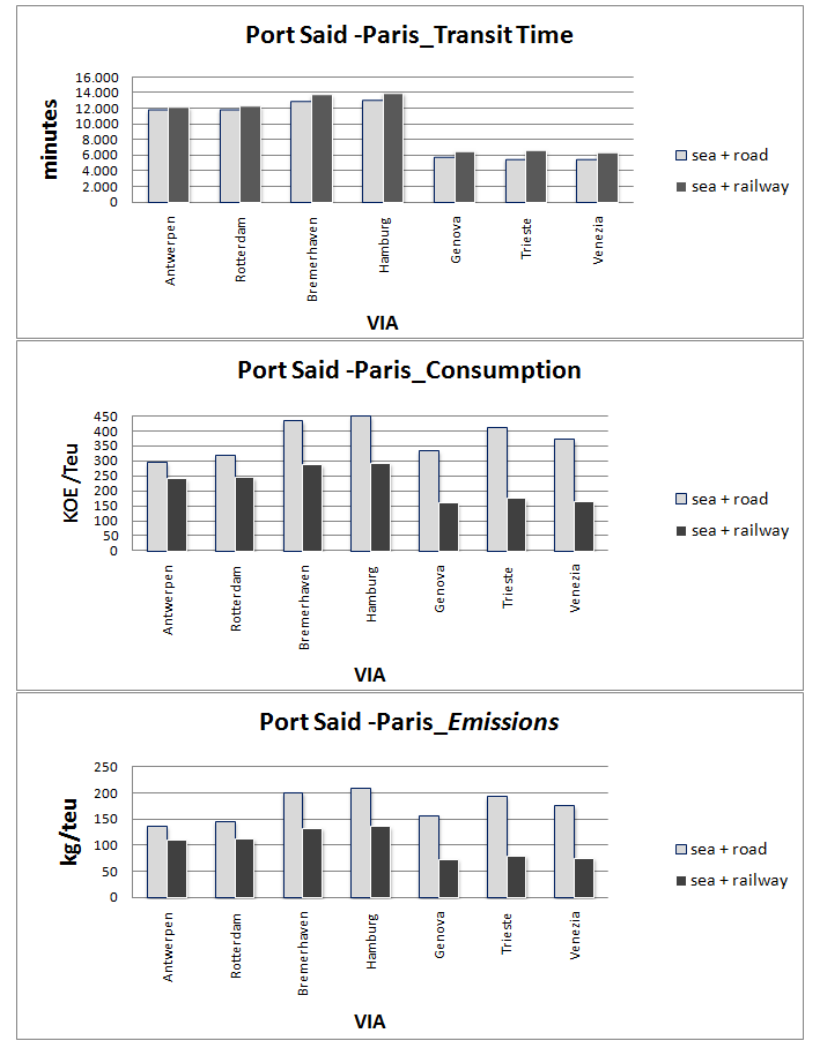

Figure 4: $\quad$ Port Said - Paris: transit time, consumption and emissions. 


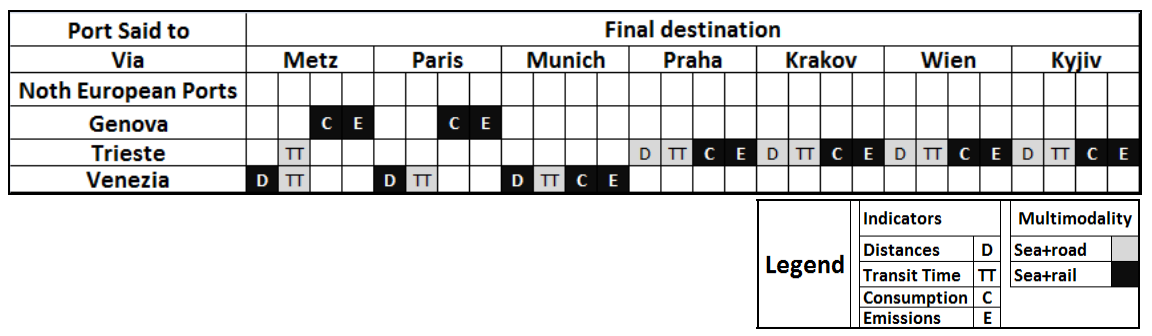

Figure 5: Best routes relating to different indicators and modes of transport.

We have noted that:

-North Adriatic ports are efficient in transportation terms for all of the examined European destination;

-North Tyrrhenian ports present a lower value only for energy consumption and emissions exclusively for the French trading area (to Metz and Paris);

-choosing a multimodal sea+road route gives best performances for all the investigated destinations in terms of transit time;

-choosing a multimodal sea+rail route gives best performances for all the investigated destinations in terms of consumption and emissions;

-the North European ports are not efficient for all the used parameters and for all the assessed destinations.

Nevertheless Atlantic Ports are the main hubs currently chosen by intercontinental shipping operators (also for shipments coming from Asia to Europe) cause of their high efficiency level (service times and costs). As the present research has underlined, this network use implies heavy environmental impacts. A deeper analysis has been carried out taking into account $\mathrm{CO}_{2}$ emissions because world interests are in reducing pollutant gases. Therefore preferring multimodal routes with less environmental impacts become a priority thinking that Carbon dioxide $\mathrm{CO}_{2}$ emissions are the prevailing share in greenhouse gases in the transport sector.

The figure 6 represents $\mathrm{CO}_{2}$ emissions from Port Said to main inland destinations (ship+rail) of multimodal routes (sea+rail) via Venezia and maritime route via Antwerp.

It has been noted that:

- maritime emissions are two times and a half greater to reach north European ports than to reach the Mediterranean ones;

- a multimodal route via Venezia plus railway systems has less carbon pollutant effects to reach inland north European destinations than the Atlantic route.

This map aims to redraw the current use of transport network depending from the origin of shipping supporting environmental sustainability. Using Adriatic or Mediterranean ports appears more sustainable for delivery from Asia to Europe. First of all it is necessary working to improve the ports and railway network performances which currently are not able to give a good level of service quality. 


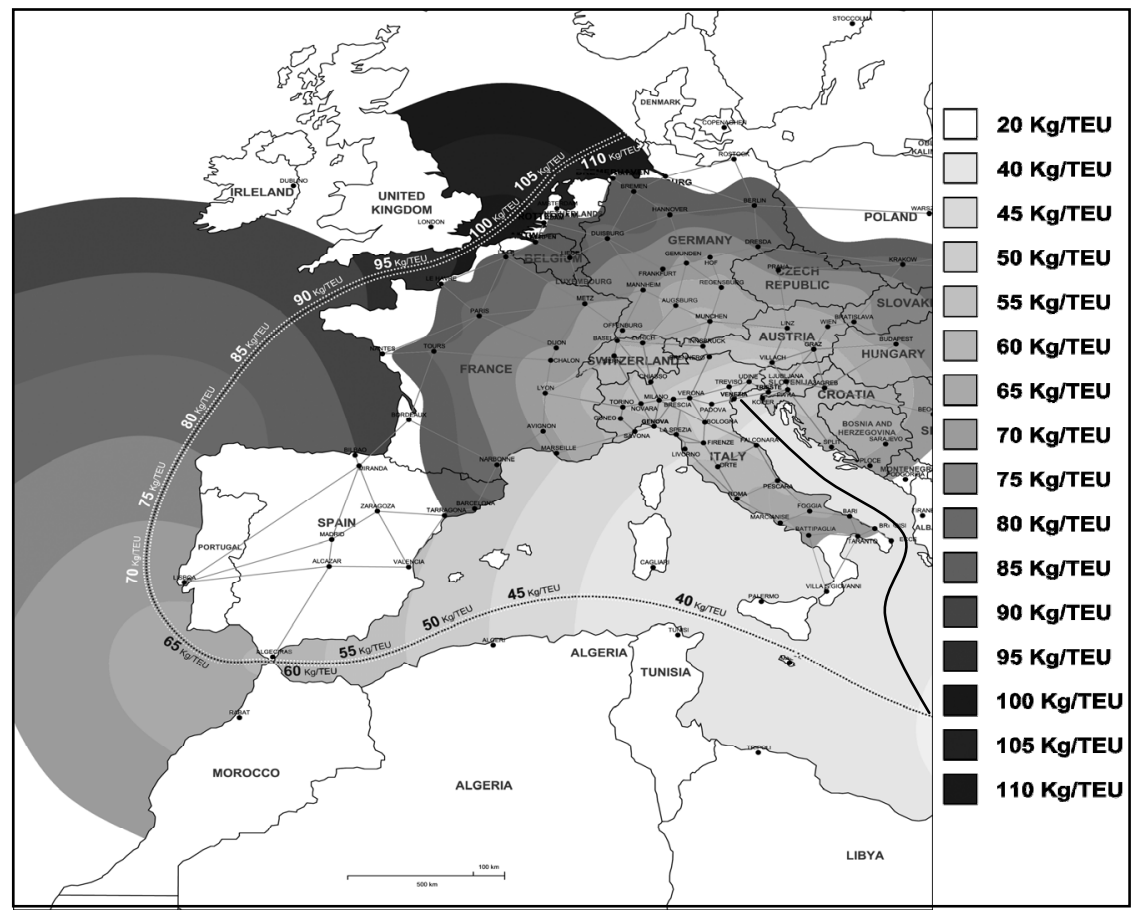

Figure 6: $\mathrm{CO}_{2}$ multimodal emissions: Port Said-inland destinations (Via Venezia) and Port Said-Atlantic ports.

\section{References}

[1] Ifeu-Institut für Energieund Umweltforschung Heidelberg $\mathrm{GmbH}$, EcoTransIT: Ecological Transport Information Tool, Heidelberg, 2008.

[2] ARPAV-Agenzia Regionale per la Prevenzione e Protezione Ambientale del Veneto, Le emissioni da attività portuale, Venezia, 2007

[3] International Union of Combined Road-Rail Transport companies, www.uirr.com

[4] Containerisation International, www.ci-online.co.uk

[5] EEA-European Environment Agency, Transport at a crossroads. TERM 2008: indicators tracking transport and environment in the European Union, Copenhagen, 2009 